\title{
Comparative Evaluation of Metabolic Syndrome in Premenopausal and Postmenopausal Women
}

\author{
*Archana Toppo1, Sanjay Varma ${ }^{2}$, Laxmikant Sahu ${ }^{3}$ \\ ${ }^{1,2-}$ Associate Professor, ${ }^{3-}$ Resident, Department of Medicine, Pt. J.N.M. Medical College Raipur (C.G.) \\ *Corresponding author: *Archana Toppo
}

\begin{abstract}
:
Background:The prevalence of the Metabolic Syndrome is increasing tremendously due to increase in obesity around the World. Metabolic Syndrome doubles the risk of Atherosclerotic Cardiovascular diseases and approximately four fold increases the risk of developing type II diabetes mellitus. It has been seen that Metabolic Syndrome is on the rising trend especially in post-menopausal women. Metabolic Syndrome is widely increasing especially in the transition phase in every woman's life from premenopausal to menopausal phase. The aim of this study is to compare presence of metabolic syndrome and its components in premenopausal and post-menopausal women.
\end{abstract}

Material and Methods: The study was conducted in 300 pre-menopausal and 300 post-menopausal women attending Medicine OPD and admitted in ward of Dr. B.R.A.M. Hospital, Raipur C.G. from March 2015 to August 2016.The objective of the study was explained and informed to women and data of each women was recorded in identical pre designed proforma after informed and written consent. Participants were categorized into two groups Pre-menopausal age group and Post-menopausal age group. Investigations including Fasting blood sugar, Lipid Profile and Anthropometric measurements including height, weight, waist circumference (WC) and hip circumference (HC) was recorded. A modified definition by the Adult Treatment Panel III guideline of the National Cholesterol Education Program was used to categorize the subjects according to presence of metabolic syndrome.

Results: In the present study the mean age of pre-menopausal and postmenopausal group was 42.8 yrs and 54.5 yrs respectively in a study group of 300 women in each. The mean age of attaining menopause in present study was $46 \pm 3.1$ yrs. Mean systolic BP in pre-menopausal and post-menopausal study group was $117.13 \pm 10.87 \mathrm{mmHg}$ and $118.23+13.15 \mathrm{mmHg}$ respectively. Mean Diastolic BP in pre-menopausal and postmenopausal study group was $78.55 \pm 8.19 \mathrm{mmHg}$ and $77.70+9.24 \mathrm{mmHg}$ respectively. No significant difference was observed between two groups regarding systolic BP $(p=0.265)$ and diastolic BP. $(p=0.234)$ The mean Waist Circumference (WC) was $78.96 \pm 8.84 \mathrm{cms}$ and $80.11 \pm 10.82 \mathrm{cms}$ in pre and post menopausal group respectively with no significant difference. Waist Hip Ratio was found to be significantly higher in postmenopausal subjects compare to pre-menopausal subjects. $(p=0.001)$. BMI was was found to be significantly higher in post-menopausal subjects as compared to pre-menopausal subjects.( $p=0.003)$. TG was found to be significantly higher in Post- menopausal subjects compared to pre -menopausal subjects ( $p<0.0001)$. HDL was found to be significantly lower in Post-menopausal subjects compared to pre- menopausal subjects $(p=0.071) . F B S$ and PPBS were found to be significantly higher in Post-menopausal subjects as compared to pre-menopausal subjects. Raised FBS levels in post-menopausal subjects was statistically significant $(p<0.0001)$ in the study. The overall prevalence of Metabolic Syndrome as per NCEP ATP III and IDF criteria was 38\% and 50.7\%. respectively in our study. The prevalence of Metabolic Syndrome in post-menopausal women as per NCEP ATP III and IDF criteria was $48.6 \%$ and 56.8\% respectively. Prevalence of Metabolic Syndrome in pre-menopausal women as per NCEP ATP III criteria is $27.4 \%$. and $44.6 \%$ as per IDF criteria. In pre-menopausal group - Among this study subjects $1.47 \%$ had five risk factors of Metabolic Syndrome, $15.3 \%$ had four, $10.43 \%$ had three, $45.9 \%$ had two risk factors while $26.9 \%$ had only one risk factor of Metabolic Syndrome. In post-menopausal group 10.2\% had five risk factors of Metabolic Syndrome and 40.32\%had four risk factors while 49.4\% had three and50.9\% had two and 36.9\% had one risk factor of Metabolic Syndrome in the study. Conclusion: In present study there was high prevalence of Metabolic Syndrome (48.6\%) among postmenopausal women than pre-menopausal women (27.4\%) The incidence of Metabolic Syndrome increases with age, peak is seen in fourth to sixth decade. Dyslipidemia and abdominal obesity were the most prevalent components of Metabolic Syndrome among these women.

Keywords: NCEP ATP III=National cholesterol Education Programme Adult Treatment Panel III, IDF= Inetrnational Diabetes Federation, EGSIR= European Group for the Study of Insulin Resistance. 


\section{Introduction}

Metabolic Syndrome (Syndrome X, Insulin resistance syndrome) is widely increasing especially in the transition phase in every woman's life from premenopausal to menopausal phase. The existence of Metabolic Syndrome was first described by Kylin in 1923 when he described metabolic syndrome as clustering of hypertension, hyperglycemia and gout. [1]Gerald Reaven in 1988 gave pathophysiological arguments for the existence of Syndrome $\mathrm{X}$, in which he included insulin resistance, hyperinsulinaemia, hyperglycemia, dyslipidemia and arterial hypertension and found that insulin resistance was present in $25 \%$ of adult population.[2] Besides insulin resistance with resulting hyperinsulinemia, the other identified features of the Metabolic syndrome include impaired glucose tolerance/type 2 diabetes, hypertension, lipid triad [increased triglycerides, decreased high-density lipoprotein cholesterol (HDL-C), increased low-density lipoprotein cholesterol (LDL-C)] ,obesity/visceral adiposity, elevation of inflammatory markers.[3]

The World Health Organization (WHO) was the first to specify the diagnostic criteria for metabolic syndrome in 1998. [4] The WHO definition emphasized insulin resistance and therefore required the individual to be insulin resistant or having type 2 diabetes, or impaired glucose tolerance (indicated by oral glucose tolerance test). The practical difficulties in meeting the insulin criteria limited the use of the WHO definition. In addition to this absolute requirement of insulin resistance, two additional criteria have to be met. These included obesity (measured as elevated waist-hip ratio or body mass index (BMI), dyslipidemia [high triglycerides or low high density lipoprotein (HDL) cholesterol], hypertension and microalbuminuria. In 1999, the European Group for the Study of Insulin Resistance (EGIR) proposed a modification of the WHO definition.[5] The WHO criteria was modified for better practical approach and the EGIR proposed their own definition relying on fasting insulin instead of the euglycaemic clamp to measure insulin resistance. Therefore, participants with type 2 diabetes were excluded since fasting insulin may not be a useful measure of insulin resistance in such persons. The obesity criteria were simplified to waist circumference. Moreover, micro albuminuria was eliminated from the criteria of metabolic Syndrome.

In 2001, the National Cholesterol Education Program (NCEP) Adult Treatment Panel III (ATP III) introduced an alternative clinical definition for metabolic syndrome. The purpose of the NCEP definition was to identify people at higher long-term risk for CVD who would need clinical lifestyle intervention to reduce risk. An updated NCEP definition was proposed by the American Heart Association (AHA) and the National Heart Lung and Blood Institute (NHLBI) in 2005. [6] This definition retained most of the NCEP ATP III criteria but suggested a lower threshold for elevated fasting glucose. The NCEP definitions one of the most widely used metabolic syndrome definition because it is practical and easy to apply. However, it does not include the measurement of insulin and therefore it may fail to take insulin resistance into account.

In 2005, the International Diabetes Federation (IDF) proposed a new definition for metabolic syndrome, which was quite similar to the NCEP definition except that central obesity was required. [4] Following are definitions of metabolic syndrome according to IDF, ATP III, WHO

\section{International Diabetes Federation definition of the metabolic syndrome:-}

In order for a person to have a diagnosis of metabolic syndrome, he or she must have. Central obesity (defined as a waist circumference $>94 \mathrm{~cm}$ for European men and $>80 \mathrm{~cm}$ for European women, with ethnicityspecific values for other groups.) - If BMI is $>30 \mathrm{~kg} / \mathrm{m}^{2}$, central obesity can be assumed and waist circumference does not need to be measured.

\section{Plus any 2 of the following $\mathbf{4}$ factors}

1. High trigliceride concentration: $\geq 150 \mathrm{mg} / \mathrm{dL}(1.7 \mathrm{mmol} / \mathrm{L})$, or specific treatment for this abnormality.

2. Low HDL-cholesterol concentration: $<40 \mathrm{mg} / \mathrm{dL}(1.03 \mathrm{mmol} / \mathrm{L})$ in males and $<50 \mathrm{mg} / \mathrm{dL}(1.29 \mathrm{mmol} / \mathrm{L})$ in females, or specific treatment for this lipid abnormality.

3. High blood pressure (BP):systolic $\geq 130 \mathrm{~mm} \mathrm{Hg}$ or diastolic $\geq 85 \mathrm{~mm} \mathrm{Hg}$, or treatment of previously diagnosed hypertension.

4. High fasting plasma glucose (FPG) concentration $\geq 100 \mathrm{mg} / \mathrm{dL}(5.6 \mathrm{mmol} / \mathrm{L})$, or previously diagnosed type 2 diabetes.

If FPG is above the values stated above, an oral-glucose-tolerance test is strongly recommended but is not necessary to define presence of the syndrome.

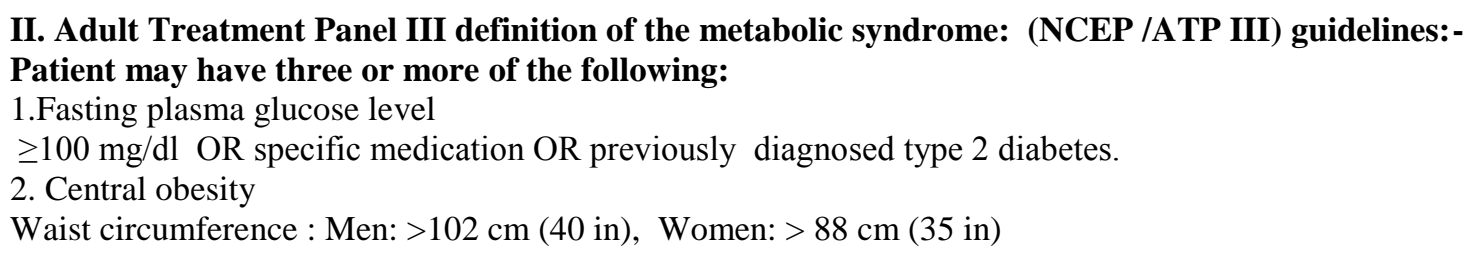


3. Triacylglyceridemia

$\geq 150 \mathrm{mg} / \mathrm{dL}(>1.7 \mathrm{mmol} / \mathrm{L})$ OR specific medication

4. Low HDL cholesterol

Men: $<40 \mathrm{mg} / \mathrm{dL}(<1.036 \mathrm{mmol} / \mathrm{L})$, Women: $<50 \mathrm{mg} / \mathrm{dL}(<1.295 \mathrm{mmol} / \mathrm{L})$ OR specific medication

5. Hypertension

Blood pressure $\geq 130 \mathrm{~mm} \mathrm{Hg}$ systolic $\mathrm{OR} \geq 85 \mathrm{~mm} \mathrm{Hg}$ diastolic OR

specific medication

III. World Health Organization definition of the metabolic syndrome:-

The patient must have 1 of the following

1. Diabetes mellitus

Fasting plasma glucose $\geq 126 \mathrm{mg} / \mathrm{dL} \geq 7 \mathrm{mmol} / \mathrm{L}$ OR

2 hour post glucose load $\geq 200 \mathrm{mg} / \mathrm{dL} \geq 11.1 \mathrm{mmol} / \mathrm{L}$

2. Impaired glucose tolerance -

Fasting plasma glucose $<126 \mathrm{mg} / \mathrm{dL}(<7 \mathrm{mmol} / \mathrm{L})$ and

2 hour post glucose load $>140 \mathrm{mg} / \mathrm{dL}(7.8 \mathrm{mmol} / \mathrm{L})$ and $<200 \mathrm{mg} / \mathrm{dL}(11.1 \mathrm{mmol} / \mathrm{L})$

3. Impaired fasting glucose -

Fasting plasma glucose $>110 \mathrm{mg} / \mathrm{dL}(6.1 \mathrm{mmol} / \mathrm{L})$ and $<126 \mathrm{mg} / \mathrm{dL}(<7 \mathrm{mmol} / \mathrm{L})$ and.(If measured 2 hour post glucose load $<140 \mathrm{mg} / \mathrm{dL}(7.8 \mathrm{mmol} / \mathrm{L})$

4.Insulin resistance:

Glucose uptake below lowest quartile for background population under investigation under hyperinsulinemic, euglycemic conditions.

Plus any 2 of the following:

1. Waist-to-hip ratio $>0.9$ in men, $>0.85$ in women; BMI $>30$; OR both

2. Triacylglycerols $>150 \mathrm{mg} / \mathrm{dL}(>1.7 \mathrm{mmol} / \mathrm{L})$

3. HDL cholesterol $<35 \mathrm{mg} / \mathrm{dL}(0.9 \mathrm{mmol} / \mathrm{L})$ in $\mathrm{men}$,

$<39 \mathrm{mg} / \mathrm{dL}(1.0 \mathrm{mmol} / \mathrm{L})$ in women; or both

4. Blood pressure $>140 / 90 \mathrm{~mm} \mathrm{Hg}$ (revised from $>160 / 90 \mathrm{~mm} \mathrm{Hg}$ )

5. Microalbuminuria (urinary albumin excretion rate $>20 \mathrm{microg} / \mathrm{min}$ OR albumin-to-creatinine ratio $>30$ mg/g. (AlbertiKG ,Zimmet PZ 1998)[4]

\section{European Group for the Study of Insulin Resistance,(EGIR) 1999:-}

Insulin resistance hyperinsulinaemia,

Plus 2 or more of the following

1. Central obesity: waist -hip ratio for men $>0.9$, for women $>0.85$ and/orBMI is $>30 \mathrm{~kg} / \mathrm{m}^{2}$

2. Dyslipidaemia: raised plasma triglycerides $>1.7 \mathrm{mmol} / \mathrm{L}$ or low HDL cholesterol $<1.0 \mathrm{mmol} / \mathrm{L}$ for women and $<0.9 \mathrm{mmol} / \mathrm{L}$ for men or treated for dyslipidemia .

3. Hypertension: blood pressure $>140 / 90 \mathrm{~mm} \mathrm{Hg}$ and/or on antihypertensive medication.

4. Fasting plasma glucose: $>6.1 \mathrm{mmol} / \mathrm{L}($ Balkau B, Charles MA 1999)[5]

\section{American Association of Clinical Endocrinologists (AACE)}

Identifying abnormalities of Insulin Resistance Syndrome

1. Triglycerides: $>150 \mathrm{mg} / \mathrm{dl}$

2. HDL: $<40 \mathrm{mg} / \mathrm{dl}$ for men, $<50 \mathrm{mg} / \mathrm{dl}$ for women

3. BP:>130/85mm Hg (Bloomgarden ZT 2003)[27]

4. Glucose :

Fasting $110-125 \mathrm{mg} / \mathrm{dl}$

$120 \mathrm{~min}$ post glucose challenge $140-200 \mathrm{mg} / \mathrm{dl}$

Table No 1 : Different Criteria of Metabolic Syndrome

\begin{tabular}{|l|l|l|l|l|l|}
\hline & WHO,1998 & NCEP ATP III,2004 & IDF,2005 & SOUTH ASIANS & $\begin{array}{l}\text { ASIAN } \\
\text { INDIANS }\end{array}$ \\
\hline $\mathrm{AC}(\mathrm{cm})$ in women & WHR $>0.85$ OR BMI $>30$ & $>88$ & $>/=80$ & $>82$ & $\geq 72$ \\
\hline $\mathrm{BP}(\mathrm{mm} / \mathrm{Hg})$ & $\begin{array}{l}\text { Sys. }>140 \\
\text { Dias. }>90\end{array}$ & $\begin{array}{l}\text { Sys. }>130 \\
\text { Dias. }>85\end{array}$ & $\begin{array}{l}\text { Sys. }>130 \\
\text { Dias. }>85\end{array}$ & $\begin{array}{l}\text { Sys. }>130 \\
\text { Dias. }>85\end{array}$ & $\begin{array}{l}\text { Sys. }>130 \\
\text { Dias. }>85\end{array}$ \\
\hline Serum TG(mg/dl) & $>150$ & $>150$ & $>150$ & $>150$ & $>150$ \\
\hline HDL(mg/dl) & $<39$ & $<50$ & $<50$ & $<50$ & $<50$ \\
\hline $\begin{array}{l}\text { Fasting } \\
\text { sugar(mg/dl) }\end{array}$ & $>110$ & $\geq 100$ & $\geq 100$ & $\geq 100$ & $\geq 100$ \\
\hline Microalbumi-nuria & $\begin{array}{l}\text { U.alb.excretion }>\text { or alb. } \\
\begin{array}{l}\text { micro/min or } \\
\text { creatinine ratio }>30 \mathrm{mg} / \mathrm{g}\end{array}\end{array}$ & & & \\
\hline
\end{tabular}


A hallmark of the menopausal transition is the dramatic reduction in estradiol levels. With this reduction, there is a progressive shift toward androgen dominance in the hormonal milieu. Although little is known about how this hormonal shift influences CVD risk, available studies suggest a link between androgenicity and CVD risk factors. The metabolic syndrome is a summary measure of important CVD risk factors that frequently coexist. The syndrome is evident in $20 \%$ to $30 \%$ of middle-aged women and has been linked to the development of CVD and diabetes.

\section{Material And Methods}

The study was conducted in 300 pre-menopausal and 300 post- menopausal women attending Medicine OPD and admitted in Medicine ward of Dr. B.R.A.M. Hospital, Raipur C.G. from March 2015 to August 2016.The objective of the study was explained and informed to women and data of each women was recorded in identical pre designed pro forma after informed and written consent. Participants were categorized into two groups

1.Pre-menopausal age group

2.Post-menopausal age group

Study Design:- Observational \& Cross sectional

Inclusion criteria for study group:-

Menopause or Post-menopause -Period that starts one year after the last menstruation. It is subdivided into early (up to five years after the last menstruation) or late (more than five years after the last menstruation).

Peri-menopause or menopausal transition - Period that extends from two years before the last menstruation and until one year later. Women have irregular menstrual cycles and endocrine changes.

Pre-menopause - Period during which women still have menstrual cycles, whether such cycles are regular or not. By definition peri-menopause will not fulfill the criteria for post-menopause, hence included in pre-menopausal group. Pre-menopausal and post-menopausal women taking specific medications for hypertension, diabetes and dyslipidemia were also included in study group.

\section{Exclusion criteria for study group:-}

Acute recent illness and/or history of any overt chronic inflammatory disease.

Patients with liver disease

Patients with renal disease

Pregnant women.

After obtaining informed consent, all participants had undergone complete general and systemic examination and investigations. Initially a questionnaire was completed containing information regarding the physical activity, leisure time, addiction, menopausal status, consumption of relevant medication specially antidiabetic, anti-hypertensive and hormone replacement therapy.

Anthropometric measurements including height, weight, waist circumference (WC) and hip circumference (HC) was taken with participants wearing light clothes and without shoes.

\section{Weight}

Weight was recorded to the nearest $0.1 \mathrm{~kg}$ using electronic digital liquid-crystal display weighing machines placed on a flat surface.

Height

Height was measured with the participant standing erect against a wall looking straight ahead with the occiput, back, hip and heels in contact with the wall.

\section{Body mass index}

Body mass index (BMI) was calculated as the weight $(\mathrm{kg})$ divided by square of the height $\left({ }^{\mathrm{m} 2}\right)$.

Body mass index $(\mathrm{BMI})=$ Weight $(\mathrm{kg}) / \operatorname{Height}\left({ }^{\mathrm{m} 2}\right)$

\section{Waist circumference}

WC was measured by placing a tape horizontally midway between the lower border of the ribs and iliac crest on the mid-axillary line.

Hip circumference

Measured at the level of iliac crest

Waist- Hip Ratio

Systolic and diastolic blood pressure

Blood pressure was measured twice in the right arm in both a sitting and standing position. Measurements were taken 5 min apart, and the mean of the two measurements was taken as the final blood pressure reading.

Biochemical analysis:- 
Blood for biochemical analysis was obtained from the participants after 10-12 hours of an overnight fast. Blood sample was taken in morning with all usual precaution in plain vial without any additives and anticoagulants , serum sample was collected after centrifugation.

Fasting blood sugar \& Postprandial blood sugar were determined by GOD / POD method.

Fasting lipid profile : Triglyceride \& HDL levels were estimated.

A modified definition by the Adult Treatment Panel III guideline of the National Cholesterol Education Program was used to categorize the subjects, which is given below Diagnostic criteria for Metabolic Syndrome

Table No 2 : NCEP-ATP III (2005)

\begin{tabular}{|l|l|}
\hline PARAMETER & NCEP-ATP III (2005) \\
\hline Abdominal circumference & $>88 \mathrm{~cm}$ \\
\hline Triglyceride & $\geq 150 \mathrm{mg} / \mathrm{dl}$ \\
\hline HDL level & $<50 \mathrm{mg} / \mathrm{dl}$ \\
\hline Blood Pressure & $\begin{array}{l}\text { Systolic }>/=130 \mathrm{mmHg} \\
\text { Diastolic }>/=85 \mathrm{mmHg}\end{array}$ \\
\hline Fasting blood glucose & $\geq 100 \mathrm{mg} / \mathrm{dl}$ \\
\hline Diagnosis of Metabolic Syndrome & Three criteria \\
\hline
\end{tabular}

The NCEP-ATP III (2005) criteria is the most frequently used criteria. But there are other criteria also which deserves to be discussed. The IDF (2005) criteria, which is almost similar to NCEP ATP III criteria is also widely accepted. The parameters are as follows-

Table No 03 : IDF (2005)

\begin{tabular}{|l|l|}
\hline PARAMETER & IDF (2005) \\
\hline Abdominal circumference & $\geq 80 \mathrm{~cm}$ \\
\hline Triglyceride & $\geq 150 \mathrm{mg} / \mathrm{dl}$ \\
\hline HDL & $<50 \mathrm{mg} / \mathrm{dl}$ \\
\hline Blood Pressure & $\begin{array}{l}\text { Systolic }>130 \mathrm{mmHg} \\
\text { Diastolic }>85 \mathrm{mmHg}\end{array}$ \\
\hline Fasting blood glucose & $\geq 100 \mathrm{mg} / \mathrm{dl}$ \\
\hline Diagnosis of Metabolic Syndrome & AC + two criteria \\
& \\
\hline
\end{tabular}

\section{Observation And Results}

The study was conducted in 300 premenopausal and 300 post menopausal women in the Department of Medicine, Dr. B.R.A.M. Hospital, Raipur and following observations were obtained.

Table No 4 : Comparison of Lipd profile parameters in pre-menopausal and post-menopausal study subjects.

\begin{tabular}{|l|l|l|l|l|l|l|l|}
\hline Characteristics & Study group & $\mathbf{N}$ & Mean & S Deviation & $\begin{array}{l}\text { Std. Error } \\
\text { Mean }\end{array}$ & $\mathbf{T}$ & $\begin{array}{l}\text { Sig. (2- } \\
\text { tailed) }\end{array}$ \\
\hline \multirow{2}{*}{ TG (mg/dl) } & $\begin{array}{l}\text { Pre- } \\
\text { menopausal }\end{array}$ & 300 & 123.21 & 31.28185 & 1.80606 & -4.626 & $<0.0001$ \\
\cline { 2 - 8 } & $\begin{array}{l}\text { Post- } \\
\text { menopausal }\end{array}$ & 300 & 137.08 & 41.45458 & 2.39338 & & \\
\hline \multirow{2}{*}{ HDL (mg/dl) } & $\begin{array}{l}\text { Pre- } \\
\text { menopausal }\end{array}$ & 300 & 38.7167 & 13.32723 & 0.76945 & & \\
\cline { 2 - 9 } & $\begin{array}{l}\text { Post- } \\
\text { menopausal }\end{array}$ & 300 & 37.1000 & 7.82864 & 0.45199 & 1.812 & 0.071 \\
\hline
\end{tabular}

Table No 5: Comparison of BP in Pre-menopausal and post-menopausal study subjects

\begin{tabular}{|c|c|c|c|c|c|c|c|}
\hline Characteristics & Study group & $\mathbf{N}$ & Mean & $\begin{array}{l}\text { Std. } \\
\text { Deviation }\end{array}$ & Error Mean & $\mathbf{t}$ & $\begin{array}{c}\text { Sig.(2- } \\
\text { tailed) }\end{array}$ \\
\hline \multirow{2}{*}{$\begin{array}{l}\text { Systolic BP } \\
\text { (mm Hg) }\end{array}$} & $\begin{array}{l}\text { Pre- } \\
\text { menopausal }\end{array}$ & 300 & 117.13 & 10.87089 & 0.62763 & & \multirow{2}{*}{0.265} \\
\hline & $\begin{array}{l}\begin{array}{l}\text { Post- } \\
\text { menopausal }\end{array}\end{array}$ & 300 & 118.23 & 13.15761 & & & \\
\hline \multirow{2}{*}{$\begin{array}{l}\text { Diastolic BP } \\
(\mathbf{m m ~ H g})\end{array}$} & $\begin{array}{l}\text { Pre- } \\
\text { menopausal }\end{array}$ & 300 & 78.5500 & 8.19786 & 0.47330 & \multirow{2}{*}{1.191} & \multirow{2}{*}{0.234} \\
\hline & $\begin{array}{l}\text { Post- } \\
\text { menopausal }\end{array}$ & 300 & 77.7000 & 9.24635 & 0.53384 & & \\
\hline
\end{tabular}


Table No 6: Comparison of waist and hip circumference in Pre- menopausal and post-menopausal study subjects

\begin{tabular}{|c|c|c|c|c|c|c|c|}
\hline Characteristics & Study group & $\mathbf{N}$ & Mean & $\begin{array}{l}\text { Std. } \\
\text { Deviation }\end{array}$ & $\begin{array}{l}\text { Std } \\
\text { Error } \\
\text { Mean } \\
\end{array}$ & $\mathbf{t}$ & $\begin{array}{l}\text { Sig. (2- } \\
\text { tailed) }\end{array}$ \\
\hline \multirow{2}{*}{$\begin{array}{l}\text { Waist } \\
\text { circumference } \\
\text { (cm) }\end{array}$} & $\begin{array}{l}\text { Pre- } \\
\text { menopausal }\end{array}$ & 300 & 78.9667 & 8.84721 & 0.51079 & \multirow{2}{*}{1.420} & \multirow{2}{*}{0.156} \\
\hline & $\begin{array}{l}\text { Post- } \\
\text { menopausal }\end{array}$ & 300 & 80.1133 & 10.82703 & 0.62510 & & \\
\hline \multirow{2}{*}{$\begin{array}{l}\text { Hip } \\
\text { circumference } \\
\text { (cm) }\end{array}$} & $\begin{array}{l}\text { Pre- } \\
\text { menopausal }\end{array}$ & 300 & 89.6900 & 8.45056 & 0.48789 & \multirow{2}{*}{0.380} & \multirow{2}{*}{0.704} \\
\hline & $\begin{array}{l}\text { Post- } \\
\text { menopausal }\end{array}$ & 300 & 89.3933 & 10.57915 & 0.61079 & & \\
\hline
\end{tabular}

Table No 7 : Association of Metabolic syndrome with Menopause

\begin{tabular}{|l|l|l|l|l|l|}
\hline & & \multicolumn{2}{|c|}{ Study Group } & & \\
\hline \multirow{3}{*}{$\begin{array}{l}\text { Metabolic } \\
\text { Syndrome }\end{array}$} & & Pre-menopausal & Post-menopausal & Total & p value \\
\cline { 2 - 5 } & $\begin{array}{l}\text { Absent } \\
\text { \% }\end{array}$ & 281 & 245 & 526 & \\
\cline { 2 - 5 } & $93.7 \%$ & $81.7 \%$ & $87.7 \%$ & \\
& Present & 19 & 55 & 74 & $<0.0001$ \\
& $\mathbf{\%}$ & $6.3 \%$ & $18.3 \%$ & $12.3 \%$ & \\
\hline \multirow{2}{*}{ Total } & $\mathbf{N}$ & 300 & 300 & 600 & \\
& $\mathbf{\%}$ & $100 \%$ & $100 \%$ & $100 \%$ & \\
\hline
\end{tabular}

\section{Results}

The study comprised of 600 women subjects with 300 candidates in both premenopausal and postmenopausal study group each. Out of 300 pre-menopausal study group most of the women were of 36 to 45 yrs age group with mean age of 42.8 yrs and in 300 post-menopausal study group mean age was 54.5 yrs in the study. The age of attaining menopause in present study lies in between 41 to 50 yrs. with mean of $46 \pm 3.1 \mathrm{yrs}$. Although $6.7 \%$ of women attained menopause in the age group of 51 to 60 yrs. Mean systolic BP in premenopausal and post-menopausal study group is $117.13 \pm 10.87$ and $118.23+13.15$ respectively. Mean Diastolic $\mathrm{BP}$ in pre-menopausal and post-menopausal study group is $78.55 \pm 8.19$ and $77.70+9.24$ respectively. No significant difference was observed between two groups regarding systolic BP $(\mathrm{p}=0.265)$ and diastolic BP. $(\mathrm{p}=0.234)$ The mean Waist Circumference $(\mathrm{WC})$ in pre-menopausal and postmenopausal study group was 78.96 $\pm 8.84 \mathrm{cms}$ and $80.11 \pm 10.82 \mathrm{cms}$ respectively. No significant difference was observed between two groups regarding waist circumference $(\mathrm{p}=0.156)$

Waist Hip Ratio was found to be significantly higher in post menopausal subjects compare to premenopausal subjects.(p=0.001). BMI was found to be significantly higher in post-menopausal subjects as compared to pre-menopausal subjects. $(\mathrm{p}=0.003) \mathrm{TG}$ was found to be significantly higher in Post- menopausal subjects compared to pre -menopausal subjects $(\mathrm{p}<0.0001)$. HDL was found to be significantly lower in Post menopausal subjects compared to pre- menopausal subjects $(\mathrm{p}=0.071)$. FBS and PPBS were found to be significantly higher in Post- menopausal subjects as compared to pre-menopausal subjects. We found raised FBS levels in post-menopausal subjects which was statistically significant $(\mathrm{p}<0.0001)$ in our study. The overall prevalence of Metabolic Syndrome as per NCEP ATP III and IDF criteria was 38\% and 50.7\%. respectively in our study. The prevalence of Metabolic Syndrome in post-menopausal women as per NCEP ATP III and IDF criteria was $48.6 \%$ and $56.8 \%$ respectively.

Prevalence of Metabolic Syndrome in pre-menopausal women as per NCEP ATP III criteria is $27.4 \%$. and $44.6 \%$ as per IDF criteria. In pre-menopausal group - Among this study subjects $1.47 \%$ had five risk factors for Metabolic Syndrome, $15.3 \%$ had four, $10.43 \%$ had three, $45.9 \%$ had two risk factors while $26.9 \%$ had only one risk factor for Metabolic Syndrome. In post-menopausal group 10.2\% had five risk factors for Metabolic Syndrome and $40.32 \%$ had four risk factors while $49.4 \%$ had three and50.9\% had two and $36.9 \%$ had one risk factor for Metabolic Syndrome in our study. The results of our study suggest that the prevalence of Metabolic Syndrome in post-menopausal women was significantly higher than pre-menopausal women. Dyslipidemia and abdominal obesity were the most prevalent components of Metabolic Syndrome among post-menopausal women in the present study.

\section{Discussion}

Metabolic Syndrome increases the risk of Cardiovascular disease as well as morbidity and mortality due to it. On the other hand, menopause with its incidental hormonal changes appears to increase the risk of CVD independently of normal aging, and premenopausal women may be protected against CVD compared with men and postmenopausal women of a similar age. The present study was intended to determine the prevalence of Metabolic Syndrome and its components in premenopausal and postmenopausal women, as well as the association between the menopausal status and Metabolic Syndrome.

DOI: 10.9790/0853-1606140109 www.iosrjournals.org $\quad 6 \mid$ Page


The mean age of pre-menopausal and post menopausal women in study group is $42.83 \pm 3.7$ yrs and $54.50 \pm 6.36$ yrs respectively. In a study done by M Nakhjavani et al 2014 the mean ages of pre-menopausal and post-menopausal were $43.33 \pm 0.47 \mathrm{yrs}$ and $60.35 \pm 0.38 \mathrm{yrs}$ respectively which is similar to our study. [7] In a study done by Miller et al 1998 where age group were $40-70$ yrs. and $60 \%$ of them were post-menopausal. They found that $68 \%$ post- menopausal women had Metabolic Syndrome and 13\% pre-menopausal women had Metabolic Syndrome. This increased prevalence in post- menopausal group may have occurred because the average age was higher (57.3 yrs.) in their study. [8]These findings indicates age as a participating factor when the relationship of menopausal status and the occurrence of Metabolic Syndrome are studied. Although the risk of Metabolic Syndrome increases with age, studies have shown that post-menopausal women are at greater risk of having Metabolic Syndrome, regardless of age.

Waist hip ratio was found to be significantly higher in post- menopausal subjects compared to premenopausal subjects $(\mathrm{p}=0.001)$ in our study. In a study by A Marjani et al 2012 Waist hip ratio was significantly high among post-menopausal women with metabolic syndrome. [9] Similarly KB Mishra et al 2006 observed significantly higher Waist/ hip ratio (WHR) $(0.87 \pm 0.07, \mathrm{p}<0.05)$ for women with metabolic syndrome as compared to those without metabolic syndrome. [10]N Chhabra et al 2013 observed that post-menopausal women had significantly higher mean WHR, than their pre-menopausal counterparts.[11]

In present study TG cholesterol levels were higher in post- menopausal study group as compared to pre-menopausal women whereas lower HDL cholesterol levels were observed in both the study groups. In a study by Kanvar et al 2014 there was no significant difference in the total cholesterol and the triglyceride levels between pre- menopausal and post-menopausal groups $(\mathrm{p}>0.005)$. However there was significant reduction in HDL and VLDL-C fraction in the post-menopausal group and a significant increase in the value of LDL-C $(p<0.005)$.[12]In another study by S Jesmin et al 2013 significant high TG levels were observed in postmenopausal women than pre-menopausal women ( $\mathrm{p}<0.05)$. However, prevalence of low HDL cholesterol levels were significantly lower in post-menopausal women than pre-menopausal women $(\mathrm{p}<0.001)$.[13]R Dosi et al 2014 revealed that post-menopausal women had significantly higher prevalence of abnormal lipid profiles(total cholesterol, LDL-C and HDL-C)as compared to their pre-menopausal counterparts.[14] In the study by F K Nanse Arthur et al 2013, there is increase in serum triglyceride levels in post- menopausal women but mean levels of HDL-cholesterol were similar between pre-menopausal and post- menopausal women.[15]

In our study FBS levels were found to be higher in post- menopausal subjects compared to premenopausal subjects with mean of $73.01 \pm 21.16$ and $77.41 \pm 24.17 \mathrm{mg} / \mathrm{dl}$ respectively which was not statistically significant. ( $\mathrm{p}=0.18)$ Significant association was detected between FBS and menopause $(\mathrm{p}<0.0001)$ indicating raised FBS levels in post-menopausal subjects. According to a study by Walton et al 1993 a significant difference of impaired fasting glucose was found among post-menopausal women with and without metabolic syndrome. Walton and colleagues also report an increase in FBS among post-menopausal women with metabolic syndrome.[16] In another study S Jesmin et al 2013 found prevalence of elevated fasting blood glucose, was significantly higher in post- menopausal women than pre-menopausal women $(p<0.05)$. [13] $\mathrm{M}$ Shalini et al 2013 found in their study that fasting blood glucose levels, were significantly higher among women with metabolic syndrome $(p=0.009351)$. [17]

The concept of Metabolic Syndrome and its grave consequences has emerged for several decades, but only after the standardization of diagnostic criteria, it was possible to evaluate the prevalence of Metabolic Syndrome in different regions. The prevalence of Metabolic Syndrome varies a lot owing to differences in genetic profile, eating habits, levels of physical activity, age, gender, lifestyle etc.

The overall prevalence of Metabolic Syndrome as per NCEP ATP III and IDF criteria was 38\% and $50.7 \%$. respectively in our study. The prevalence of Metabolic Syndrome in post-menopausal women as per NCEP ATP III and IDF criteria was $48.6 \%$ and 56.8\% respectively. Prevalence of Metabolic Syndrome in premenopausal women as per NCEP ATP III criteria is $27.4 \%$. and $44.6 \%$ respectively as per IDF criteria. In a study by Jesmin et al 2013 the overall prevalence of Metabolic Syndrome was $25.6 \%$ where 39.3\% of postmenopausal women and $16.8 \%$ of pre-menopausal women had Metabolic Syndrome which is statistically significant $(\mathrm{p}<0.001)$.[13]According to study by FK Nanse Arthur et al 2013 the percentage prevalence of Metabolic Syndrome was $14.4 \%, 25.6 \%, 29.2 \%$ and 30.4\% using WHO, NCEP ATP III, IDF and H_MS criteria respectively for the total population. The prevalence was higher among the post- menopausal group (i.e. $25.2 \%$, $41.1 \%, 43.0 \%$ and $43.9 \%$ for WHO, NCEP ATP III, IDF and H_MS respectively) compared to the premenopausal population (i.e. $6.3 \%, 14.7 \%, 18.9 \%$ and $23.1 \%$ respectively for WHO, NCEP ATP III, IDF and H_MS criteria respectively) The prevalence of metabolic syndrome was significantly higher among postmenopausal women ( $\mathrm{p}<0.05$ by all criteria) compared to their pre-menopausal cohort, but with marked intercriteria variations in his study.[15] In A study by Zahra Jouyandeh et al 2013 overall prevalence of metabolic syndrome among study subjects was $30.1 \%$ by NCEP ATP III criteria. Waist circumference, HDL cholesterol, fasting blood glucose, diastolic blood pressure ,Systolic blood pressure, and triglyceride were significantly higher among women with metabolic syndrome $(\mathrm{p}<0.05$. There is high prevalence of abdominal obesity and 
hypertension which were the most prevalent components of metabolic syndrome.[18] In a study by S Pandey et al 2010 prevalence of metabolic syndrome amongst post-menopausal women was significantly higher ( $\mathrm{p}<$ 0.001 ) than that in pre-menopausal women by both, IDF (pre-menopausal $45 \%$ and post- menopausal 55\%) and H_MS criteria (pre-menopausal $44 \%$ and post- menopausal 56\%). However, this significance disappeared when data was adjusted for the confounding variable of age. [19]A S Sapkota et al 2015 in their study observed that the prevalence of Metabolic Syndrome was found to be 57.8\% in postmenopausal and 20\% in premenopausal women using the IDF criteria. Metabolic Syndrome was highly prevalent in postmenopausal women than in premenopausal women.[20] Eshtiaghi et al 2010, showed a prevalence of 53.5\% Metabolic Syndrome in postmenopausal Iranian women, on the other hand it was only $18 \%$ in pre-menopausal women.[21] The overall prevalence of Metabolic Syndrome in a study by Samir Ben Ali et al 2014 was 35.9\%. They found that the prevalence of Metabolic Syndrome was significantly higher among postmenopausal women (45.7\%) than among premenopausal women (25.6\%).[22]

The mechanisms underlying the association between menopausal transition and Metabolic Syndrome have not fully been elucidated. The decline in ovarian function is considered the main cause of this phenomenon.[23] In premenopausal and postmenopausal women, the prevalence of metabolic syndrome were 8.69\% and 21.85\%, respectively in a study done by Jong Kil Joo et al 2012.[24] Neto et al 2010 estimated prevalence of the syndrome among Brazilian pre-and postmenopausal women to be $24.0 \%$ and $44.4 \%$ according to NCEP ATP III criterion. [25] Similarly, the prevalence of the syndrome was $13.8 \%$ and $54.6 \%$ among Korean pre-and postmenopausal women respectively in a study by Kim H et al 2007.[26]Our findings were consistent with many of previous studies where post-menopausal women have been found to be at higher risk of Metabolic Syndrome than pre-menopausal women. These differences in prevalence of metabolic syndrome in different studies can be due to different investigation methods of the syndrome. Asian Indians have different anthropometric characteristics in comparison with white Caucasians and blacks. Metabolic abnormalities contributing to CV risk factors are detectable at a lower WC in Asians. Hence, using NCEP ATP III, IDF, WHO, EGIR and AACE criteria might underestimate the prevalence of Metabolic Syndrome in Asians. In our study deranged lipid profiles i.e. high Triglyceride levels with low HDL levels were most predominantly observed followed by increased Waist Circumference. So Dyslipidemia and abdominal obesity were the most prevalent components of Metabolic Syndrome among these women although Hypertension and Impaired Fasting blood sugar levels were also the risk factors observed in our study. The results of our study suggest that the prevalence of Metabolic Syndrome in post-menopausal women was significantly higher than premenopausal women.

\section{Conclusion}

In our study there was high prevalence of Metabolic Syndrome (48.6\%) among post-menopausal women than pre-menopausal women (27.4\%) The incidence of Metabolic Syndrome increases with age, peak is seen in fourth to sixth decade. Dyslipidemia and abdominal obesity were the most prevalent components of Metabolic Syndrome among these women. Although Indians have lower average WC by virtue of their smaller body size, they carry excess morbidity risks even at lower BMI. It should be made a point to incorporate measurements of Height, Weight, Waist Hip Ratio, Blood Pressure and blood investigations as FBS and lipid profile estimation in routine by all Physicians. Many patients were ignorant about the Metabolic Syndrome and its complications so women who are showing derangements but not meeting the criteria of Metabolic Syndrome should be taught about lifestyle changes so as to check the disease at its infancy and reduce the hidden burden of future cardiovascular complications and morbidity. Prevention through changes in lifestyle, or early detection and treatment of elevated fasting blood glucose, hypertension, and hyperlipidemia are necessary for prevention of many chronic diseases in women reaching after menopausal status. Health professionals should consider the post-menopausal women as a major target group for prevention of Metabolic Syndrome, which is an underlying condition of many non -communicable diseases.

\section{Acknowledgement}

The authors would like to thank staff of Department of Medicine, Pt. J.N.M.Medical College, Raipur and also to authors/editors/publishers of all those articles, journals and books from where the literature for this article has been reviewed and discussed.

\section{References}

[1]. Kylin E (1923) Studien uber das Hypertonie-Hyperglykamie- Hyperurikamiesyndrom. Zentralbl Inn Med 44:105-127

[2]. Reaven G. Metabolic syndrome: pathophysiology and implications for management of cardiovascular disease. Circulation. 2002;106:286-288.

[3]. Arnold A, Caulin-Glaser T, Gulanski B, Insulin Resistance Explains Elevated Crp In Diabetics. Circulation 2001; 104(S-Ii): 834854. 
[4]. Alberti KG, Zimmet P, Shaw J. Metabolic syndrome: a new world-wide definition: a consensus statement from the International Diabetes Federation. Diabet Med. 2006;23:469-480.

[5]. Balkau B, Charles M, Comment On The Provisional Report From The Who Consultation. European Group For The Study Of Insulin Resistance (EGIR). Diabetes Med 1999; 16:442-443.

[6]. Grundy S, Brewer H, Jr., Cleeman Ji, Definition Of Metabolic Syndrome: Report Of The National Heart, Lung, And Blood Institute/ American Heart Association Conference On Scientific Issues Related To Definition. Circulation 2004; 109: 433-438.

[7]. Nakhjavani M, Imani M, Larry M, Aghajani-Nargesi A, Morteza A, Esteghamati A. Metabolic syndrome in premenopausal and postmenopausal women with type 2 diabetes: loss of protective effects of premenopausal status. J Diabetes Metab Disord. 2014;13(1):102.

[8]. Miller VM, Black DM, Brinton EA, Budoff MJ, Cedars MI, et al. (2009) Using basic science to design a clinical trial: Baseline characteristics of women enrolled in the Kronos Early Estrogen Prevention Study (KEEPS). J Cardiovasc Trans1 Res 2: 228-239.

[9]. Marjani A, Moghasemi S: The Metabolic Syndrome among Postmenopausal Women in Gorgan. Int J Endocrinol 2012 , 202. doi:10.1155/2012/953627. Article ID 953627, 6 pages

[10]. Misra KB, Endemann SW, Ayer M. Leisure time physical activity and metabolic syndrome in Asian Indian immigrants residing in northern California. Ethn Diseases. 2005;15:627-634.

[11]. N.Chhabra, Kuldip Sodhi , Sahiba Kukreja, Vijayasarathy S, Sarah Chhabra , Central Obesity And Prevalence Of Metabolic Syndrome In Post-Menopausal Women, Jan 2014. Webmed Central Obesity 2014;5(1):WMC004532

[12]. Kanwar R, Narang A, Sastry A, Marwaha RK, Tandon N, Garg MK et al. Bone health status in healthy Indians aged 50 years and above. Osteoporos Int 2011;22:2829-2836.

[13]. Subrina Jesmin, MdReazul Islam, A M Shahidul Islam, MdSohag Mia, SayeedaNusrat Sultana, SohelZaedi, Naoto Yamaguchi, Yoshio Iwashima, Michiaki Hiroeand Tetsu Watanabe, Comprehensive Assessment Of Metabolic Syndrome Among Rural Bangladeshi Women, Bmc Public Health 2012, 12:49.

[14]. Rupal Dosi, Nikita Bhatt, Priyanki Shah, Rushad Patell, Cardiovascular Disease and Menopause, Original Article DOI : 10.7860/JCDR/2014/6457.4009, 2014 Feb;Vol 8 (2) : 62 - 64

[15]. Fareed K N Arthur, Michael Adu-Frimpong, James Osei-Yeboah, FaustinaO Mensahand Lawrence Owusu, Prediction of metabolic syndrome among postmenopausal Ghanaian women using obesity and atherogenic markers, Lipids in Health and Disease 2012,11:101. 94

[16]. Walton C, Godsland I, Proudler A, Wynn V, Stevenson J: The effects of the menopause on insulin sensitivity, secretion and elimination in nonobese, healthy women. European J Clin Invest 1993, 23(8):466-473.

[17]. Shalini M., Suresh Babu K.P., and Vaishnavi B., Metabolic Syndrome among Urban And Rural Women Population - A Cross Sectional Study, Journal of Clinical And Diagnostic Research, 2013 Sep; 7(9): 1938-1940.

[18]. Jouyadeh Z, Nayebzadeh F, Qorbani M, Asadi M. Metabolic syndrome and menopause. J Diabetes Metab Disord. 2013;12(1).

[19]. S.Pandey,M.Srinivas,S.Agashe,J.Joshi,P.Galvankar,C.P.Prakasar,R. Vaidya, MenopauseAnd Metabolic Syndrome: A Study Of 498 Urban Women From Western India,J Midlife Health, 2010 Jul- Dec;1(2)63-69.

[20]. Alina Shri Sapkota, Alisha Sapkota, Kumananda Acharya, Mithileshwer Raut, Bharat Jha, Study of metabolic syndrome in postmenopausal women. ACCLM 1 2015(1) 6-11

[21]. Eshtiaghi R, Esteghamati A, Nakhjavani M. Menopause is an independent predictor of metabolic syndrome in Iranian women. Maturitas. 2010;65(3):262-266.

[22]. Samir Ben Ali et al, Hindawi Publishing Corporation BioMed Research International Volume 2014, Article ID 457131, 7 pages http://dx.doi.org/10.1155/2014/457131

[23]. C. Gohlke-B" arwolf, —Coronary artery disease - is menopause a risk factor?॥ Basic Research in Cardiology,2000; Vol. 95:1, pp. $\mathrm{I} / 77-\mathrm{I} / 83$,

[24]. Neto J, Figueredo E, Barbosa J, Barbosa F, Costa G, Nina V, Nina R: Metabolic Syndrome and Menopause: Cross-sectional Study in Gynaecology Clinic. Sociodade Braziera de Cardiologia 2010, 4:20-27.

[25]. Jong Kil Joo, M.D., Jung Bin Son, M.D., Ju Eun Jung, M.D., Seung Chul Kim, M.D., Kyu Sup Lee, M.D. Differences of Prevalence and Components of Metabolic Syndrome according to Menopausal Status J Korean Soc Menopause 2012;18:155-162

[26]. Kim H, Park J, Ryu S, Kim J: The Effect of Menopause on MetabolicSyndrome among Korean Women: the Korean National Health and Nutrition Examination Survey, 2001. Diabetes Care 2007, 30(3):701-706

[27]. Bloomgarden ZT, Fat metabolism and diabetes: American Diabetes Association postgraduate course. Diabetes Care. 2003 Jul;26(7):2198-2203 